\title{
Evolution of Consumers' Preferences due to Innovation
}

\author{
Rolan M. Dahlan \\ Dept. of Evolutionary Economics, \\ Bandung Fe Institute \\ email: rd@evonomics.bandungfe.net
}

\author{
Hokky Situngkir \\ Dept. of Computational Sociology, \\ Bandung Fe Institute \\ email: hs@compsoc.bandungfe.net
}

\begin{abstract}
The integration process between evolutionary approach and conventional economic analysis is very essential for the next development of economic studies, especially in the fundamental concepts of modern economics: supply and demand analysis. In this presentation, we use the concept of meme to explore evolution of demand. This study offers an evolutionary model of demand, which views utility as a function of the distance between the two types of sequences of memes (memeplex), which represent economic product and consumer preference. It is very different from the conventional approach of demand, which only views utility as a function of quantity. This modification provides an opportunity to see innovation and transformation of consumer preferences in the demand perspective. Innovation is seen as a change in sequence of memes in economic products, while the transformation of consumer behavior is defined as a change in the aligning memes of consumer preference. Demand quantity is the result of the selection process. This model produces some interesting characteristics, such as: (i) quantitative and qualitative properties of evolution of demand, (ii) relationship between consumer behavior and properties of evolution of demand that occurred and (iii) power law on the distribution of product lifetime. At the end we show the improvement of utility function, in the concept of meme, might create a new landscape for the further development of economics.
\end{abstract}

\section{Keywords}

Evolutionary economics, memetics, demand, evolution, innovation, transformation of consumer behavior. 


\section{Introduction}

In 1890, Alfred Marshall created a "machinery" to enhance the Adam Smith's system: the principles of supply and demand [1,2]. He compared supply and demand to the combination of the blades of scissors, each is necessary to determine price. This approach is one of the fundamental concepts of modern economics and responsible in transforming "political economy" into the science of "economics" [3]. Thus, Marshall was an influential figure in the development of neoclassical economics, or today, we can comfortably refer to mainstream economics. On the other side, Joseph Schumpeter challenged the dynamic conception of the economy in place of the static structure of economics [4]. The works of Marshall and Schumpeter are commonly perceived as two of opposite perspectives: the stereotyped view on Marshall as the synthesizer of neoclassical economics and on Schumpeter as the theorist of economic development.

Marshall would never have said that all problems are solved forever at the moment. He was fully aware that he was building an essentially temporary theoretical structure. This perspective carried on an evolutionary vision that, in his own words:

\section{"make economic biology the Mecca of the economist and not mechanics" [5]}

Schumpeter asserted himself as one of the first economists to realize that economics is an evolutionary science [6]. Unfortunately, this evolutionary perspective was not taken seriously [7,8]. His contributions to economic analysis are well-recognized, but his evolutionary economics seems to have fallen on barren ground.

In the early 1980s, evolutionary economics emerged as a branch of economic theory [9]. The difference between the mainstream economics and evolutionary economics is more clearly appreciated if we introduce the idea of qualitative changes: development of economic systems is not just a bigger replica of previous times [10]. It contains new entities that have different qualitative properties. The idea of qualitative change gives an opportunity to capture three important phenomena in economic life: innovations, product substitutions and transformation of consumer behaviors. Conventional economic analysis is developed with an assumption of identical product. In reality, no different firms produce identical products. There is a competition or substitution between new products and old products, either of the same or different firms.

In spite of the fact that evolutionary economics gives an opportunity for a more realistic view on economy, it has some problems. First, cultural or economic evolution is not equal with biological evolution. Second, there is no relational structure to communicate between evolutionary perspective and conventional economic analysis.

The first problem can be solved by using memetics point of view. Richard Dawkins introduced this concept in motivation of seeing the cultural evolution in the sense of natural selection [11]. Memetics is now widely learned as complex adaptive system [12]. One of practical and realistic standpoint in economic problem, we can view meme being the evolutionary cultural object as the smallest unit of information by which we can identify and use to explain the evolution process [13]. This outlook gives us 
some progressive results, ranging from the arrival of new method to infer or estimate the evolutionary history and relationship among empirical data of cultural and economic objects [14-19], simulating the innovation of technological artifacts [20], and memetic engineering [21-24].

At the present time the main puzzle is only the second one, the Marshall's integration, or how to assimilate and bridge the gap between evolutionary perspective and conventional economic analysis, specifically in the fundamental concepts of modern economics: supply and demand analysis. In this presentation, we use memetics approach to study economic evolution. This exploration is limited to the demand side, which is just only one single blade of the Marshall's scissors.

\section{Proposal}

Economics is the science which studies human behavior as a relationship between given ends and scarce means which have alternative uses [25]. The fundamental economic problem is about scarcity and choice since there are only a limited amount of resources available to produce the unlimited amount of goods and services we desire. In economics, choice is typically explained by using the concept of utility: the amount of satisfaction or pleasure that somebody gains from consuming a commodity or service. The basic problem is how to measure utility. We try to observe this problem as a measurement process. There are two components in measurement process: object and device. In economic choice, an economic product is a "measurement object" and consumer preference becomes a "measurement device". Economic products and consumer preference transform over time dynamically.

The first primary element of evolution of demand a.k.a.: consumer preferences on products in market, is innovation. Entrepreneurial innovation destroys the value of existing physical and human capital in order to emerging the new value of the new ones [4]. Economic product continues to grow from time to time $[26,27]$. Consider, for example, the development of computing device (from punched card technology to modern computers), mobile telephone (from analog cellular telephony to wideband mobile communication), photographic equipment (from camera obscura to digital camera), and so on.

The second primary element of demand progress is transformation of the consumer preference's itself over time and evolutionary epochs. Conventional model of economic analysis assumes that consumer's preferences are fixed and exogenous to the influence of market competitors [28]. In real life, individual consumer changes her product preferences [4]. A consumer does not select a product simply by perceiving product attributes, but their preferences are modified by the behavior of others [29-30].

Evolution of demand process is explored by using memetics point of view. There are two kinds of (sequences of) memes (memeplex) represent an economic products and signify a consumer's preference. Innovation is defined as the change in sequence of memes on particular economic product. Thus, transformation of consumer behaviors can be viewed as collective changes in the sequence of meme in the minds of consumers reflecting preferences over products. Here, consumer's utility is formulated from the "distance" between sequence of memes as reflected by the economic products 
and the memes of consumer's preference. We choose to use the Hamming distance approach, which is modified by incorporating asymmetric factor between economic product and consumer preference.

\section{Model}

Meme is defined as the smallest unit of information that replicates [13]. Memes will compound memeplex, the sequence of memes, where in memetic process expressed in certain way as the phemetype, i. e., traits or characteristics or feature. Memetic process is defined as the function of

$$
\mu: M \rightarrow C
$$

$M$ expresses the set of memetype, $C$ as phemetype, and $\mu$ as the function that correlates between memetype and phemetype. In general, memetype is the memeplex coalesces from number of particular meme. Each meme (a) will have a particular value which is called allomeme (values of meme). Thus, when we deal with memeplex constituted by $N$ number of memes, we can denote the memeplex $i$ as

$$
M_{i}=a_{i, 1} a_{i, 2} a_{i, 3} \ldots a_{i, N}
$$

Allomemes related to cultural artifact can be stated as "yes" or "no" over the proposition of certain character, trait or feature representing particular artifact [13]. In this model, there are two types of memeplex, represent an economic product $(\bar{M})$ and signify a consumer preference $(\widehat{M})$. We represent allomeme of consumer preference and economic product as binary number of " 0 " or " 1 " (see table 1 ). $\bar{M}$ and $\widehat{M}$ are assumed have equal number of memes $(N)$.

Table 1

Interpretation of allomeme (values of meme).

\begin{tabular}{|l|c|c|}
\hline \multirow{2}{*}{ Questions } & \multicolumn{2}{c|}{ Answers } \\
\cline { 2 - 3 } & Yes & No \\
\hline Does agent $j$ expect feature number $n$ ? & $\widehat{a}_{j, n}=1$ & $\widehat{a}_{j, n}=0$ \\
\hline Does feature number $n$ exist in product $i$ ? & $\bar{a}_{i, n}=1$ & $\bar{a}_{i, n}=0$ \\
\hline
\end{tabular}

There are 3 kinds of processes that occur in every round $(t)$ : first is the innovation process, second is the process of transformation of consumer preferences, and third is the selection process. 


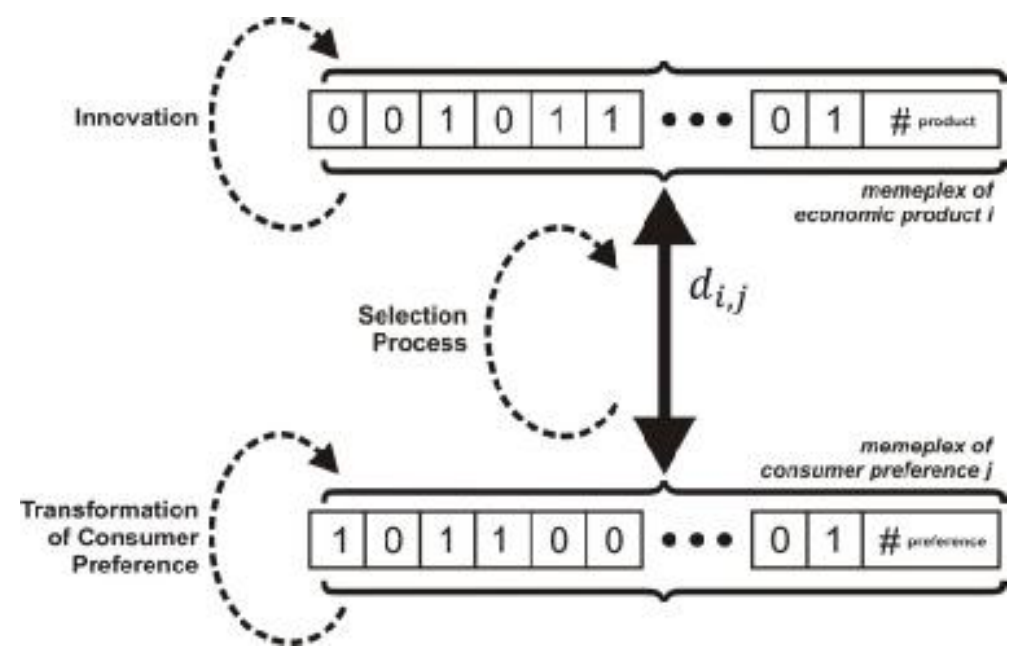

Figure 1

The illustration of the model. Notation \# is the head of memeplex, indicating that they have the same basic functions (products that can be substituted or preferences that could influence each other).

\section{Innovation Process}

Economic product continues to grow from time to time [26]. These qualitative change phenomena can be studied in evolutionary perspective [23]. By adopting memetics perspective $[14,20]$, we can explore innovation by adapting the genetic algorithms approach. Innovation is defined as the change in memeplexes of economic product $(\bar{M})$, due to mutation or crossover process [32-34].

The mutation rate $\left(\varphi_{m}\right)$ is defined as probability of mutation at a particular meme. This process occurs with the following rules

$$
\bar{M}_{m}(t)=\bar{M}^{n}(t-1) \rightarrow \bar{M}^{n *}(t)
$$

Crossover rate $\left(\varphi_{c}\right)$ is defined to be the probability that two memeplex of economic product will cross over in a single point and produce a new product, where

$$
\bar{M}_{c}(t)=\bar{M}^{n 1}(t-1) \otimes \bar{M}^{n 2}(t-1)
$$

By definition, it is worth noting that we are not saying that memes are in the economic products. Our notion of meme here, is related to how a product perceived cognitively by consumers (and producers).

\section{Transformation of Consumer Preference}

There is an endogenous process in the evolution of consumer preferences [28-31]. Their orientation is determined by the behavior of other consumers. Transformation of consumer behavior can be viewed 
as an evolutionary process involving changes in the memeplex of consumer preference $(\widehat{M})$. This direction can be accommodated simply by using Sznajd model $[35,36]$, a simple version of the onedimensional Ising spin model [37] that aims to explain the evolution of opinion in a closed community. But in practice, to avoid the unrealistic 50-50 alternating final state, we use a modified version [38].

Consumers are placed in a ring-shaped topology. Every round $(t)$, we randomly select several pairs of meme, with probability $\varphi_{f}$, that will affect the behavior of nearest neighbors.

$$
\begin{array}{ccc}
\text { if } \hat{a}_{j, n}(t-1)=\hat{a}_{j+1, n}(t-1) & \rightarrow & \left\{\begin{array}{c}
\hat{a}_{j-1, n}(t)=\hat{a}_{j, n}(t-1)=\hat{a}_{j+1, n}(t-1) \\
\hat{a}_{j+2, n}(t)=\hat{a}_{j, n}(t-1)=\hat{a}_{j+1, n}(t-1)
\end{array}\right\} \\
\text { if } \hat{a}_{j, n}(t-1) \neq \hat{a}_{j+1, n}(t-1) & \rightarrow \quad\left\{\begin{array}{c}
\hat{a}_{j-1, n}(t)=\hat{a}_{j, n}(t-1) \\
\hat{a}_{j+2, n}(t)=\hat{a}_{j+1, n}(t-1)
\end{array}\right\}
\end{array}
$$

\section{Selection Process}

At initial condition, there are $I$ unique economic products and $J$ consumers. The transformation of consumer preferences only changes the characteristic of consumer preferences, but the number of consumers is fixed. Different conditions occur in the innovation process, at the middle of a round; this process will generate new products. At the end of a particular round, each product selected. Number of products in the beginning and at the end of a round is assumed to be fixed.

The selection process uses modification of Hamming distance, by adding asymmetric factor between consumer's inclination (or disinclination) and product's ability (or inability) to satisfy. This characteristic is accommodated by incorporating asymmetric factor between $\bar{M}$ and $\widehat{M}$. Distance $(d)$ to the feature or meme $n$ between economic product $i$ and agent $j$ is formulated as

$$
d_{i, j}^{n}(t)=\left|\bar{a}_{i, n}(t)-\beta \cdot \hat{a}_{j, n}(t)+(\beta-1)\right|
$$

$\beta$ can be defined as the toughness level of agents to their preferences (see table 2), where $0 \leq \beta \leq 1$ : if $\beta=0$ then agents are very easy to moderate their preferences and if $\beta=1$ then agents are very confidence to their preferences. If $\beta=1$ then equation (vi) becomes the standard Hamming distance.

\begin{tabular}{|c|c|c|c|}
\hline \multirow{2}{*}{\multicolumn{2}{|c|}{$d_{i, j}^{n}$}} & \multicolumn{2}{|c|}{$\bar{a}_{i, n}$} \\
\hline & & 1 & 0 \\
\hline$\hat{a}_{i, n}$ & 1 & 0 & 1 \\
\hline$u_{J, n}$ & 0 & $\beta$ & $1-\beta$ \\
\hline
\end{tabular}

Table 2

Distance relationship between preference of consumer and product's ability (or inability) to satisfy.

Utility $(u)$ agent $j$ to product $i$ is defined as

$$
u_{i, j}(t)=\sum_{n=1}^{N} \omega^{n}\left(1-d_{i, j}^{n}(t)\right)
$$


$\omega^{n}$ is the weight of feature $n$. If $\omega^{\#}$ is the weight of the basic function (\#) then value $(w)$ of product $i$ can be calculated by

$$
w_{i}(t)=\sum_{n=1}^{N}\left[\left(\bar{a}_{i, n}(t) \cdot \omega^{n}\right)+\omega^{\#}\right]
$$

Every round, every agent $j$ chose a product that provides the maximum value of utility per price $(p)$, or $u / p$. If we assume $p_{i} \sim w_{i}$ then decision $(q)$ of agent $j$ to product $i$ can be formulated as

$$
q_{i, j}(t)= \begin{cases}1 & \text { if } \quad \frac{u_{i, j}(t)}{w_{i(t)}}=\max \left(\frac{u_{1, j}(t)}{w_{1}(t)}, \frac{u_{2, j}(t)}{w_{2}(t)}, \frac{u_{3, j}(t)}{w_{3}(t)}, \ldots\right) \\ 0 & \text { else }\end{cases}
$$

From this procedure, we can calculate the demand quantity in each product or $\sum_{\forall j} q_{i, j}(t)$. Number of products in the beginning and at the end of a round is assumed to be fixed: $I$ number of economic products continues to survive, which have the highest demand value or $w_{i}(t) \cdot \sum_{\forall j} q_{i, j}(t)$. The others become extinct.

\section{Simulation and Analysis}

To investigate this model, we perform a computational simulation process. Our experimental parameters can be seen in table 3. There are four types of variables that will be explored $\left(\varphi_{m} ; \varphi_{c} ; \varphi_{f} ; \beta\right)$.

Table 2

Simulation parameters.

\begin{tabular}{|l|c|c|}
\hline \multicolumn{1}{|c|}{ Parameter } & Notation & Value \\
\hline $\begin{array}{l}\text { initial number of products in the } \\
\text { beginning of each round }\end{array}$ & $I$ & 10 \\
\hline number of agents & $J$ & 1000 \\
\hline number of memes in a memeplex & $N$ & 10 \\
\hline number of rounds & $T$ & 1000 \\
\hline initial probability $(\rho)$ of each allomeme & $\rho(a=1) \& \rho(a=1)$ & 0.5 \\
\hline weight of feature $n$ & $\omega^{n}$ & $N[0.5,0.1]$. \\
\hline weight of the basic function (\#) & $\omega^{\#}$ & 0.1 \\
\hline
\end{tabular}

\section{Quantitative Properties}

Each configuration of variables produces different output behaviors. Quantitative properties that arise can be categorized into 2 states:

- Stable Condition: there is no change in demand quantity for all rounds, or $\forall_{t}: \sum_{\forall j} q_{i, j}(t)=$ $\sum_{\forall j} q_{i, j}(1)$.

- Demand Dynamics: quantity of demand varies with the round, or $\exists_{t}: \sum_{\forall j} q_{i, j}(t) \neq \sum_{\forall j} q_{i, j}(1)$. 
Illustration of the 2 states of quantitative properties can be observed in figure 2 .
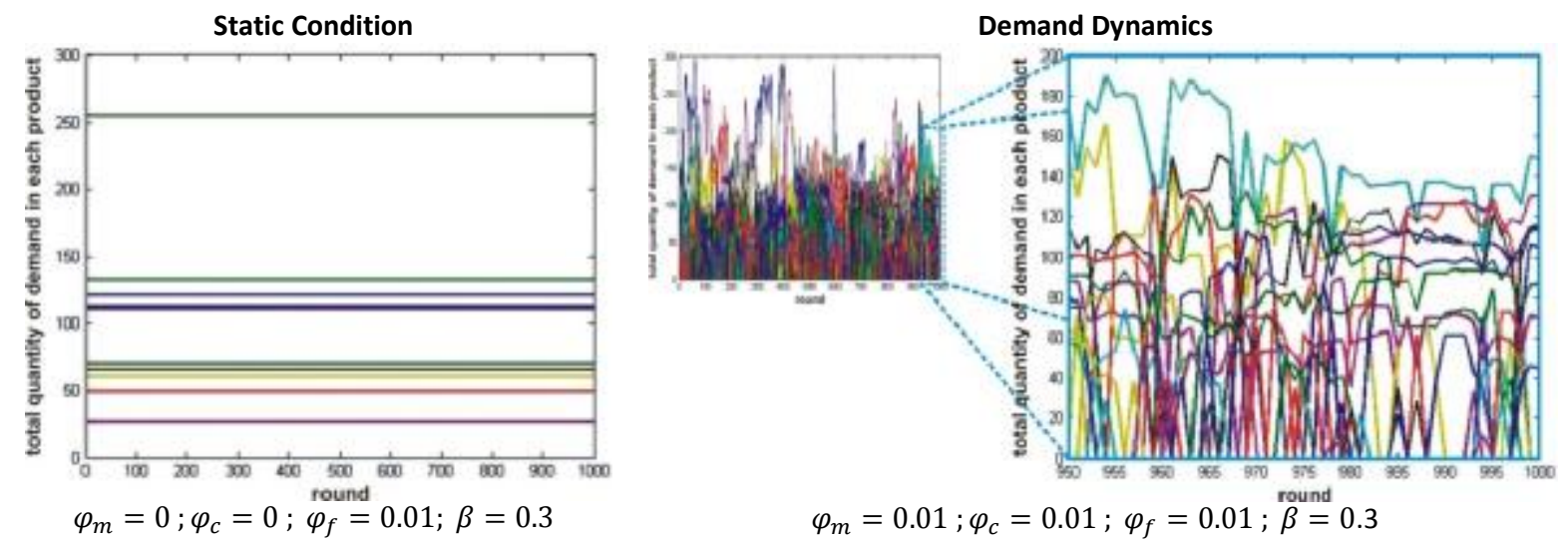

Figure 2

Illustration of 2 states of quantitative properties: Stable Condition (left) and Demand Dynamics (right).

Table 3

State of quantitative properties in various types of simulation variables.

\begin{tabular}{|c|c|c|c|c|}
\hline \multirow[b]{2}{*}{$\begin{array}{c}\text { Toughness Level } \\
\text { of Agents to Their } \\
\text { Preferences } \\
\beta\end{array}$} & \multicolumn{2}{|c|}{$\begin{array}{c}\text { Without Innovation } \\
\varphi_{m}=0 ; \varphi_{c}=0\end{array}$} & \multicolumn{2}{|c|}{$\begin{array}{c}\text { With Innovation } \\
\varphi_{m}=0.01 ; \varphi_{c}=0.01\end{array}$} \\
\hline & $\begin{array}{c}\text { Without the } \\
\text { Transformation of } \\
\text { Preferences } \\
\varphi_{f}=0\end{array}$ & $\begin{array}{c}\text { With } \\
\text { Transformation } \\
\text { of Preferences } \\
\varphi_{f}=0.01\end{array}$ & $\begin{array}{c}\text { Without the } \\
\text { Transformation } \\
\text { of Preferences } \\
\varphi_{f}=0\end{array}$ & $\begin{array}{c}\text { With } \\
\text { Transformation } \\
\text { of Preferences } \\
\varphi_{f}=0.01 \\
\end{array}$ \\
\hline 0 & \multirow{11}{*}{ Stable Condition } & & \multirow{11}{*}{ Demand Dynamics } & \\
\hline 0.1 & & & & \\
\hline 0.2 & & & & \\
\hline 0.3 & & & & \\
\hline 0.4 & & & & \\
\hline 0.5 & & & & \\
\hline 0.6 & & & & \\
\hline 0.7 & & & & \\
\hline 0.8 & & & & \\
\hline 0.9 & & & & \\
\hline 1.0 & & & & \\
\hline
\end{tabular}

We can observe the state of quantitative properties shown in table 3 . In the condition without innovation $\left(\varphi_{m} \cap \varphi_{c}=0\right)$ and without a transformation of consumer preferences $\left(\varphi_{f}=0\right)$, stability exists: there is no change in quantity of consumer's demand for all rounds. If innovation ( $\left.\varphi_{m} \cup \varphi_{c}>0\right)$ or transformation of consumer preferences $\left(\varphi_{f}>0\right)$ are there, a dynamic patterns of demand appears. Based on those investigations, we can see that the dynamics of demand may occur due to innovation or transformation of consumer preferences. This happens at all values of $\beta$. Demand dynamics occurs because the change of selection objects (products) or changes in the fitness function (consumer 
preferences). This model assumes a constant value of $\beta$, so the fitness function will not change, unless the transformations of consumer preferences exist. It explains why toughness level of agents to their preferences $(\beta)$ has no effect on the quantitative properties.

\section{Qualitative Properties}

As we conduct computational experiments over the model, it is obvious that there are at least 5 regimes of outcomes (identified as the qualitative properties) emerge (see figure 3), i.e.:

- Absolute Change: no product survives in the long term.

- Inferior: there is only one product that continues to survive in the long term: the most inferior product $\left(i^{<}\right)$, where $\forall_{n}: \bar{a}_{i^{<}, n}=0$.

- Superior: there is only one product that continues to survive in the long term: the most superior product $\left(i^{>}\right)$, where $\forall_{n}: \bar{a}_{i^{>}, n}=1$

- Quasi Stable: system moves toward a stable condition, there are one or several product continue to survive in the long term, which is not $i^{<}$or $i^{>}$.

- Absolute Stable: no new product that appears, qualitative properties are absolutely fixed.
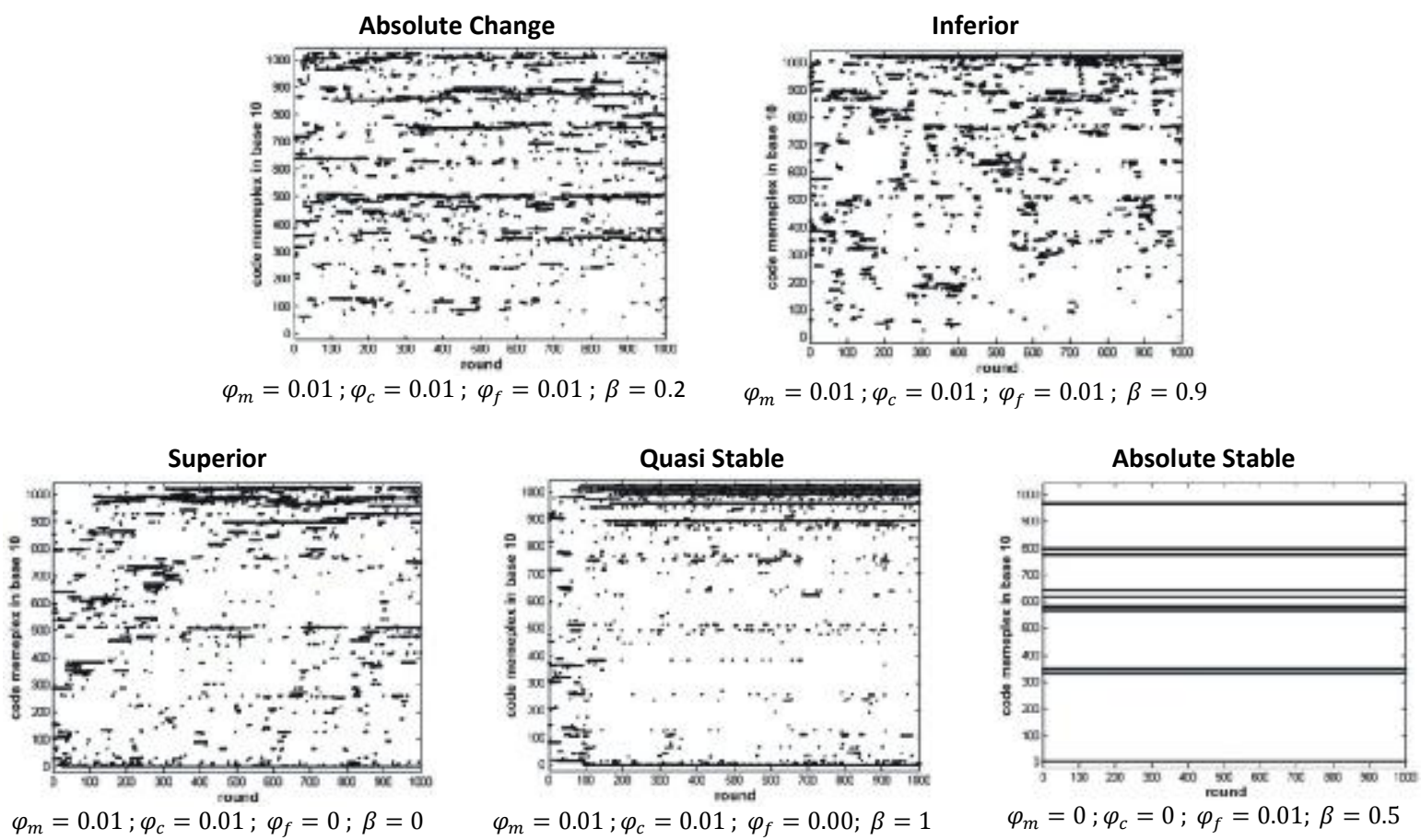

Figure 3

Memeplexes that live in a particular round in 5 states of qualitative properties: Absolute Chage (top left), Inferior (top right), Superior (bottom left), Quasi Stable (bottom center) and Absolute Stable (bottom right). 
Each configuration of the variables has different state of qualitative properties, as shown in table 4 . On the condition without innovation $\left(\varphi_{m} \cap \varphi_{c}=0\right)$, for all values of $\beta$, there comes the absolute stable regime. This is plausible since there is no appearance of new products on each round.

Four other states are driven by innovation $\left(\varphi_{m} \cup \varphi_{c}>0\right)$. In certain values of $\beta$, innovation without the transformation of consumer preferences $\left(\varphi_{f}=0\right)$, yields a quasi stable condition in the market. Innovation and transformation of consumer preferences, which took place simultaneously $\left(\left(\varphi_{m} \cup\right.\right.$ $\left.\varphi_{c}\right) \cap \varphi_{f}>0$ ), causes absolute stable regimes and quasi stable ones do not appear, for all values of $\beta$. In this situation there are 3 regimes that emerged (regimes of superior, inferior and absolute change), depending on the value of $\beta$.

Table 4

State of qualitative properties in various types of simulation variables.

\begin{tabular}{|c|c|c|c|c|}
\hline \multirow{2}{*}{$\begin{array}{l}\text { Toughness Level } \\
\text { of Agents to Their } \\
\text { Preferences } \\
\beta\end{array}$} & \multicolumn{2}{|c|}{$\begin{array}{l}\text { Without Innovation } \\
\varphi_{m}=0 ; \varphi_{c}=0\end{array}$} & \multicolumn{2}{|c|}{$\begin{array}{c}\text { With Innovation } \\
\varphi_{m}=0.01 ; \varphi_{c}=0.01\end{array}$} \\
\hline & $\begin{array}{c}\text { Without the } \\
\text { Transformation of } \\
\text { Preferences } \\
\varphi_{f}=0\end{array}$ & $\begin{array}{c}\text { With } \\
\text { Transformation } \\
\text { of Preferences } \\
\varphi_{f}=0.01\end{array}$ & $\begin{array}{c}\text { Without the } \\
\text { Transformation of } \\
\text { Preferences } \\
\varphi_{f}=0\end{array}$ & $\begin{array}{c}\text { With Transformation } \\
\text { of Preferences } \\
\varphi_{f}=0.01\end{array}$ \\
\hline 0 & \multirow{11}{*}{\multicolumn{2}{|c|}{ Absolute Stable }} & Superior & \multirow{2}{*}{ Superior } \\
\hline 0.1 & & & Quasi Stable & \\
\hline 0.2 & & & Absolute Change & \multirow{2}{*}{ Absolute Change } \\
\hline 0.3 & & & \multirow{4}{*}{ Inferior } & \\
\hline 0.4 & & & & \multirow{7}{*}{ Inferior } \\
\hline 0.5 & & & & \\
\hline 0.6 & & & & \\
\hline 0.7 & & & \multirow{4}{*}{ Quasi Stable } & \\
\hline 0.8 & & & & \\
\hline 0.9 & & & & \\
\hline 1.0 & & & & \\
\hline
\end{tabular}

In real life, innovation and consumer preferences transformation occur simultaneously. The simulation results for this realistic condition showed an interesting characteristic. If agents tend to be strongly confident with their preferences (denoted by the closeness of $\beta$ to unity) then the system reveals the inferior regime. Here, simple products tend to be accepted morel widely in the market. If agents tend to change their preferences easily (or $\beta$ close to 0 ) then the regime for superior regime rules, or in other words, complicated products are more widely preferred. Interesting characteristics occur when $\beta$ is between 0.2 and 0.3 .

The regime of absolute change is yielded between the superior $(\beta<0.2)$ and inferior $(\beta>0.3)$ conditions evolutionarily speaking. For further elaboration, we can see (in figure 4) average demand quantity or $\left\langle\sum_{\forall j} q_{i, j}(t)\right\rangle$ versus value $\left(w_{i}\right)$. In this transition state, product value tends to be insensitive to adjust the demand quantity. Complicated products and simple products tend to have the same opportunities when competing in the market. 

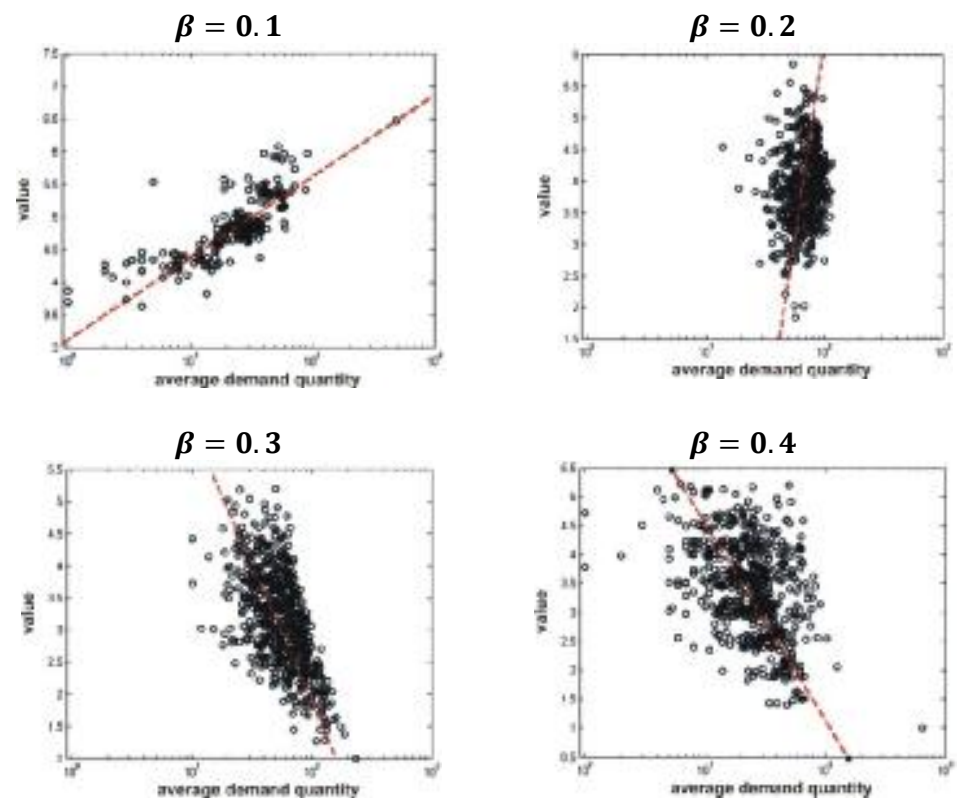

Figure 4

Average demand quantity versus value of the simulation results $\left(\varphi_{m}=0.01 ; \varphi_{c}=0.01 ; \varphi_{f}=0.01\right)$.

At the superior and inferior regimes, the demand distribution has two peaks (bimodal distribution), see figure 5. However, in absolute change regime, the demand distribution has only one peak (unimodal distribution). This is another perspective in viewing absolute change state as a transition region between the superior and inferior regime.

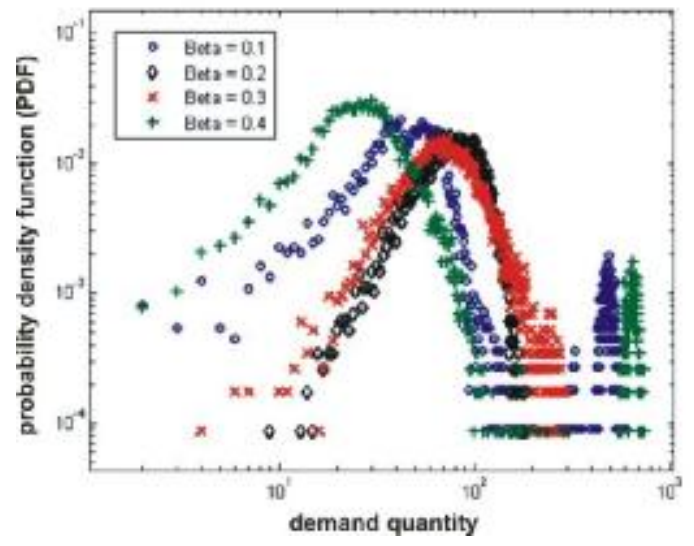

Figure 5

Probability density function of demand quantity $\left(\varphi_{m}=0.01 ; \varphi_{c}=0.01 ; \varphi_{f}=0.01\right)$.

\section{Discussion}

This presentation offers an evolutionary model of demand, which views the utility as the function of the distance between the two types of sequences of memes (memeplex), which represent economic 
product and consumer preference (see equation vii). It is a potential improvement from those of conventional economic models of demand [39], which only views utility as a function of quantity. Improvement of utility functions is needed to accommodate some important phenomena in economic life, such as innovation, product substitution and transformation of consumer preferences. In further studies, the perspective of this model and conventional model (to the utility) can be applied simultaneously: they do not contradict each other.

The result of this modification gives interesting results. From this simulation, we show that dynamics of demand may arise due to innovation or transformation of consumer preferences. Qualitative changes only occur if the innovation exists. However, innovation without the transformation of consumer preferences can push the system back toward a quasi-stable condition. Innovation and transformation of consumer preferences, which occurred simultaneously, will drive the system away from a stable condition. In this condition, other factor that plays a role: toughness level of agents to their preferences $(\beta)$.

If we combine the states of quantitative property and qualitative property then we can define 4 types of demand characteristics, due to the existence (or absence) of innovation and transformation of consumer preferences, as shown in table 5. There are 4 demand conditions, namely: "Static Demand", "Dynamic Demand without Evolution", "Limited Evolution of Demand" and "Sustainable Evolution of Demand".

Table 5

4 demand conditions, resulting from the process simulation, due to the existence (or absence) of innovation and transformation of preferences.

\begin{tabular}{|c|c|c|}
\hline $\begin{array}{c}\text { Demand } \\
\text { Conditions }\end{array}$ & Without Innovation & Innovation Exist \\
\hline $\begin{array}{c}\text { Without the } \\
\text { Transformation of } \\
\text { Preferences }\end{array}$ & $\begin{array}{c}\text { "Static Demand" } \\
\text { nomand dynamics and no } \\
\text { qualitative change }\end{array}$ & $\begin{array}{c}\text { "Limited Evolution of Demand" } \\
\text { dynamics of demand, but the qualitative } \\
\text { properties can be trapped into a quasi } \\
\text { stable condition }\end{array}$ \\
\hline $\begin{array}{c}\text { Transformation of } \\
\text { Preferences Exist }\end{array}$ & $\begin{array}{c}\text { "Demand Dynamics without } \\
\text { Evolution" } \\
\text { only the dynamics of demand, not } \\
\text { evolution }\end{array}$ & $\begin{array}{c}\text { "Sustainable Evolution of Demand" } \\
\text { demand dynamics and full qualitative } \\
\text { change, except for the most superior } \\
\text { and inferior products }\end{array}$ \\
\hline
\end{tabular}

Another interesting property of this model is the emergence of power laws [40] on the distribution of product lifetime. We define product lifetime as the period between birth and extinction of a particular product (or a memeplex). Power law behavior occurs when innovation and transformation of consumer preferences exist or $\left(\varphi_{m}=0.01 ; \varphi_{c}=0.01 ; \varphi_{f}=0.01\right)$, for all values of $\beta$. Figure 6 shows the cumulative distribution function of product lifetime (rounds). Calculation process [41] of the simulation results show that they follow the power law distribution or $p(x) \sim x^{-\alpha}$. Values of exponent or scaling parameter $(\alpha)$ vary between 2.2 to 3.5. If $\beta$ tend to become large, then the values of $\alpha$ tend to be smaller. 


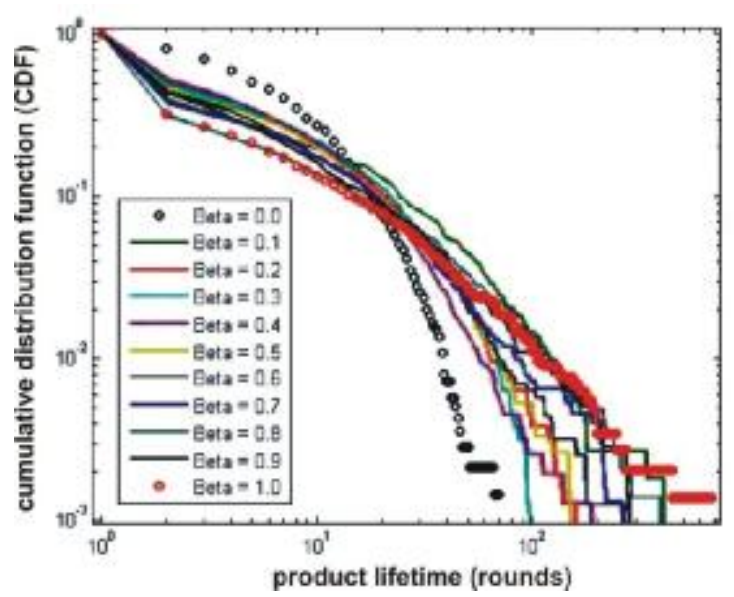

Figure 6

Cumulative distribution function of product lifetime (rounds), where $\varphi_{m}=0.01 ; \varphi_{c}=0.01 ; \varphi_{f}=0.01$.

As homework for further approach, should compare our results with the empirical data. This is, however, not included as the motivation of the paper. Nonetheless, intuitively one is conjectured to find similar results on empirical distribution of economic product lifetime (the period between birth and extinction). There are several studies that might direct us to this intuitive proposal though. The empirical relationship between the frequency and size of extinctions of largest firms is described well to have a power law distribution [42]. Other facts are the product life-span in a store (the period between the time when it first becomes available at a store and the final time when it is sold) that is shown to follow an exponential distribution [43].

\section{Conclusions}

Innovation of products and the transformation of consumer preferences is a thing that is directly related to the concavity of demand function and its dynamics. While innovation is the primary cause of qualitative change, innovation without the transformation of consumer preferences can push the system back toward a quasi stable condition. In real life, innovation and consumer preferences transformation occur simultaneously. Our experiments show that this will bring the economic system move away from a stable condition evolutionarily.

Furthermore, how easy economic agents change their preferences $(\beta)$ also plays a major role. When agents tend to hardly change their preferences (as denoted by $\beta$ close to 1 (or 0 ) then simple (complicated) product tends to be more widely accepted. Interestingly, the regime of absolute change appears between the superior and inferior regime. We show that innovation and transformation of consumer preferences will ensure the sustainable demand evolution. In the most realistic conditions (innovation and transformation of consumer preferences exist), our simulation produces power law behavior on the distribution of product lifetime, for all values of $\beta$. 
The assimilation process between evolutionary approach and conventional economic analysis is very essential for the further development of economic studies, especially in the fundamental concepts of modern economics: supply and demand analysis. Modification of the concept of utility is an alternative that potentially can be used to bridge the gap. This expansion is needed to accommodate some important phenomena in economic life, such as innovation, product substitution and transformation of consumer preferences. The improvement of utility function, in the concept of meme, might create a new landscape for the further development of economics.

\section{Acknowledgement}

The authors thank the colleagues in Bandung Fe Institute for discussions and inputs. This research was financially supported by Surya Research International. All possible mistakes remain authors'.

\section{References}

[1] Smith, A. (1776) An Inquiry Into the Nature and Causes of the Wealth of Nations, ElecBook Classics.

[2] Marshall, A. (1997) Principles of Economics, Prometheus Books.

[3] Skousen, M. (2001) The Making of Modern Economics: The Lives and Ideas of The Great Thinkers, M.E. Sharpe, Inc.

[4] Schumpeter, J. (1939) Business Cycles: A Theoretical, Historical and Statistical Analysis of the Capitalist Process, McGraw-Hill.

[5] Groenewegen, P. (2007) Alfred Marshall: Economist 1842-1924, Palgrave Macmillan.

[6] Schumpeter, J. (1997) Ten Great Economists: From Marx to Keynes, Routledge, Taylor \& Francis Group.

[7] Raffaelli, T. (2003) Marshall's Evolutionary Economics, Routledge, Taylor \& Francis Group.

[8] Shionoya, Y. and T. Nishizawa (2008) Marshall and Schumpeter on Evolution: Economic Sociology of Capitalist Development, Edward Elgar.

[9] Nelson, R. and S. Winter (1982) An Evolutionary Theory of Economic Change, The Belknap Press Of Harvard University Press.

[10] Saviotti, P. P. (2003) Applied Evolutionary Economics: New Empirical Methods and Simulation Techniques, Edward Elgar.

[11] Dawkins, R. (1989) The Selfish Gene, Second Edition, Oxford University Press.

[12] Sartika, T. D. (2004) Tracing Cultural Evolution Through Memetics, Working Paper Series WPF2004, Bandung Fe Institute.

[13] Situngkir, H. (2004) On Selfish Memes: Culture as Complex Adaptive System, Working Paper Series WPG2004, Bandung Fe Institute.

[14] Khanafiah, D., H. Situngkir (2004) Innovation as Evolution: Phylomemetic of Cellphone Designs, Working Paper Series WPV2004, Bandung Fe Institute.

[15] Situngkir, H. (2008) Evolutionary Clustering in Indonesian Ethnic Textile Motifs, Working Paper Series WP-VII-2008, Bandung Fe Institute.

[16] Situngkir, H. (2008) Constructing the Phylomemetic Tree: Indonesian Tradition-Inspired Buildings, Working Paper Series WP-III-2008, Bandung Fe Institute.

[17] Situngkir, H. (2008) Conjectures to the Memes of Indonesian Songs, Working Paper Series WP-VI-2008, Bandung Fe Institute.

[18] Situngkir, H. (2008) Memetics of Ethno-clustering Analysis, Working Paper Series WP-3-2009, Bandung Fe Institute.

[19] Situngkir, H. (2009) The Phylomemetics of Batik, Working Paper
Series WP-8-2009, Bandung Fe Institute.

[20] Khanafiah, D., H. Situngkir (2006) Innovation as Evolutionary Process, Working Paper Series WPA2006, Bandung Fe Institute.

[21] Situngkir, H. (2008) The Computational Generative Patterns in Indonesian Batik, Working Paper Series WP-V-2008, Bandung Fe Institute.

[22] Situngkir, H. (2008) Deconstructing Javanese Batik Motif: When Traditional Heritage Meets Computation, Working Paper Series WP-XIII-2008, Bandung Fe Institute.

[23] Khanafiah, D., and H. Situngkir (2009) Computational Batik Motif Generation: Innovation of Traditional Heritage by Fractal Computation, Working Paper Series WP-2-2009, Bandung Fe Institute.

[24] Situngkir, H. (2010) Exploitation of Memetics for Melodic Sequences Generation, Working Paper Series WP-2-2010, Bandung Fe Institute.

[25] Robbins, L. (1932) An Essay on the Nature and Significance of Economic Science, Macmillan.

[26] Payson, S. (1995) Product Evolution: What it Is and How it Can Be Measured, Eastern Economic Journal, Vol. 21, No. 2, Spring 1995, p.247-262.

[27] Leon, N. (2006) Trends and patterns of evolution for product Innovation, shorter versions of this paper were presented at the Altshuller Institute Conference, TRIZCON2006, Milwaukee, WI USA, April 2006 and at the First IberoAmerican Congress on Technical Innovation, Puebla, MX, September 2006.

[28] Garcia-Torres, M. A. (2009) Consumer Behaviour: Evolution of Preferences and The Search for Novelty, Working Papers No. 2009-005, United Nations University.

[29] Krackhardt, D. (1994) Endogenous Preferences: A Structural Approach, The Heinz School of Public Policy and Management, Carnegie Mellon Universty.

[30] Bisin, A. and T. Verdier (2001) The Economics of Cultural Transmission and the Dynamics of Preferences, Journal of Economic Theory, No. 97, p. 298-319.

[31] Bentley, R. A. and P. Ormerod (2009) Tradition Versus Fashion in Consumer Choice, arXiv No. 0902.2976v1, physics.soc-ph, 17 February 2009.

[32] Gen, M. and R. Cheng (1997) Genetic Algorithms \& Engineering Design, Joh Willey \& Sons.

[33] Coley, D. A. (1999) An Introduction to Genetic Algorithms for Scientists and Engineers, World Scientific Publishing.

[34] Mitchell, M. (1999) An Introduction to Genetic Algorithms, Fifth 
Printing, MIT Press.

[35] Sznajd-Weron, K. and J. Sznajd (2000) Opinion Evolution In Closed Community, Int. J. Mod. Phys. C, Vol. 11, No. 6, p. 1157.

[36] Sznajd-Weron, K (2005) Sznajd Model and Its Applications, Acta Physica Polonica B, Vol. 36, No. 8, p. 1001-11.

[37] Cipra, B. A. (1987) An Introduction to the Ising Model, The American Mathematical Monthly, Vol. 94, No. 10, p. 937-59.

[38] Sanchez, J. R. (2004) A modified one-dimensional Sznajd Model, arXiv:cond-mat/0408518v1.

[39] Varian, H. R. (1992) Microeconomic Analysis, Third Edition, W. W. Norton and Company.

[40] Newman, M. E. J. (2006) Power laws, Pareto distributions and
Zipf's Law, arXiv:cond-mat/0412004 v3.

41] Clauset, A., C. R. Shalizi, and M. E. J. Newman (2009) Power-Law Distributions In Empirical Data, arXiv:0706.1062v2

[42] Ormerod, P., H. Johns, L. Smith (2003) An Agent-Based Model of the Extinction Patterns of Capitalism's Largest Firms, Volterra Consulting.

[43] Ueno, H., T. Watanabe and M. Takayasu (2010) Life-span Distributions of Supermarket Products, Journal of Physics, Conference Series No. 221/012018, IOP Publishing. 